\title{
Variation of Magnetic Fluid Deformation Related to Nanoparticle Concentration in Steady Electric Field
}

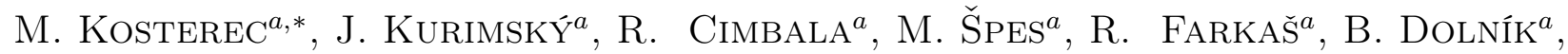

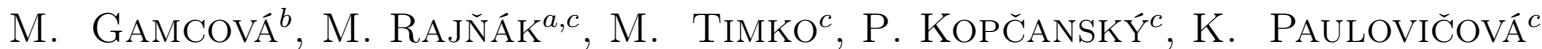 \\ AND B. VARGOVÁ ${ }^{d}$ \\ ${ }^{a}$ Department of Electrical Power Engineering, Technical University of Košice, \\ Faculty of Electrical Engineering and Informatics, Mäsiarska 74, 04120 Košice, Slovakia \\ ${ }^{b}$ Department of Electronics and Multimedia Telecommunications, Technical University of Košice, \\ Faculty of Electrical Engineering and Informatics, Vysokoškolská 4, 04120 Košice, Slovakia \\ ${ }^{c}$ Institute of Experimental Physics SAS, Watsonova 47, 04001 Košice, Slovakia \\ ${ }^{d}$ Institute of Parasitology SAS, Hlinkova 3, 04001 Košice, Slovakia
}

\begin{abstract}
Today, it is important to know the behaviour of magnetic fluids applied in the power electrical machines, e.g. in power transformers, when exposed to an electric field. Besides their promising applications in high voltage engineering, they are of increasing interest from designed assembly and pattern formation point of view. The structure of such magnetic fluids is easily controllable by external magnetic fields. However, less attention has been paid to structural phenomena in magnetic fluids induced by electric fields. The core of this paper is dedicated to the experimental observation of a magnetic fluid droplet deformation in a steady electric field. The mutual relation between the deformation parameter and magnetic nanoparticles concentration is analysed. Spatio-temporal analysis of the droplet shape is presented in the paper. The phenomena of the droplet deformation were recorded by a camera. The detailed experimental procedure is presented. The method of deformation parameter calculation based on the linear pixel as the smallest-size unit in digital image is written. Finally, the relation between the deformation parameter and the nanoparticle volume concentration, as well as the time and magnitude of the DC field application are thoroughly evaluated. The results show that the deformation parameter decreases with increasing concentration at constant applied steady electric field but increases with increasing applied steady electric field.
\end{abstract}

DOI: $10.12693 /$ APhysPolA.133.570

PACS/topics: 47.65.Cb, 41.20.-q, 47.55.D-

\section{Introduction}

Magnetic fluids (MF) are materials composed of nanosized magnetic particles dispensed in base fluid. The MF has improved electric, mechanical and thermal properties and it has the fluidity of base fluid [1-4]. MF are characterized by the ability to use external electric or magnetic field to create fluid movement [5-7]. Recently these fluids have been in the state of research in the use as an insulating alternative over mineral oils in power transformers. It is important to know the behaviour of MF when external electric, magnetic or thermal field is applied. Therefore the aim of current researches is to determine their stability when used in power transformers [3]. The first experimental and analytical observations of drop deformation in electric field conducted O'Konski and Thacher [8]; Allan and Mason [9]; Taylor [10]. The electro kinetic model is a combination of two immiscible liquids with the same or different physical properties, where one liquid is in the form of a drop and the other liquid is a carrier medium. After applying an external electric field an electrokinetic

*corresponding author; e-mail: michal.kosterec@tuke.sk phenomena occurs, electrophoresis specifically [11]. Influence of electric field on the charge carriers creates a tangential motion of a MF droplet with respect to an adjacent surface. The deformation of a droplet in the presence of electric field is based on two basic models that differ from each other by the structure of the liquid system. These two models are ideal dielectric model and a leaky dielectric model. The ideal model is described by O'Konski and Thacher, and the leaky model by Taylor. Recently we have reported lacunarity analysis of MF drop placed and a dielectric carrier fluid on glass surface under electric field [12]. The main objective of this paper is to analyse the deformation parameter of MF droplet on the surface of base fluid under exposition to an external electric field.

\section{Materials and Methods}

Magnetic fluid (MF) consists of transformer oil Mogul and $\mathrm{Fe}_{3} \mathrm{O}_{4}$ magnetic nanoparticles which concentration is $0.15 \%, 0.35 \%, 0.65 \%$ and $0.95 \%$ volume of transformer oil. Magnetic fluid was prepared according to [13].

The design and implementation of the experimental set-up were based on the research of Jong-Wook Ha et al. [14]. The set-up consisted of high voltage power supply and two copper electrodes placed in a Petri dish 
(Fig. 1). The diameter of Petri dish is $9 \mathrm{~cm}$. The electrode system consisted of two copper electrodes and the distance between them was $3 \mathrm{~cm}$. Copper electrode consisted of 2 parts. Part A is an effective area with dimensions $90 \times 10[\mathrm{~mm}]$ (Fig. 2) and part B which suppled DC voltage to part $A$ from high voltage generator (UNILAP ISO $5 \mathrm{kV})$. To eliminate inhomogeneous electric field, electrodes were shaped into Rogowski electrodes [15]. Using a wire drop of MF was placed on a silicon oil between two electrodes in a Petri dish. The desired diameter of nondeformed drop of MF was $3 \mathrm{~mm}$. After placing drop of MF an electric field was applied. The deformation of MF was recorded by camera Benq CD C750. Data were analysed after experiment using computer and processing procedures of digital images was used to obtain outline shape of droplet. Counting pixels of the image method was used to determine the deformation of MF droplet. Nondeformed MF droplet had a diameter of $3 \pm 0.2 \mathrm{~mm}$. The final determination of the deformation parameter value was obtained using $\mathrm{Eu} .(1)$ :

$$
D=\frac{a_{\|}-a_{\perp}}{a_{\|}+a_{\perp}},
$$

where $a \|$ is a distance parallel to applied electric field from centre to edge of a drop and $a_{\perp}$ is distance perpendicular to applied electric field from centre to edge of a drop. For the experimental purposes of this work, four types of MF with different volume concentrations were used and two analyses were performed.

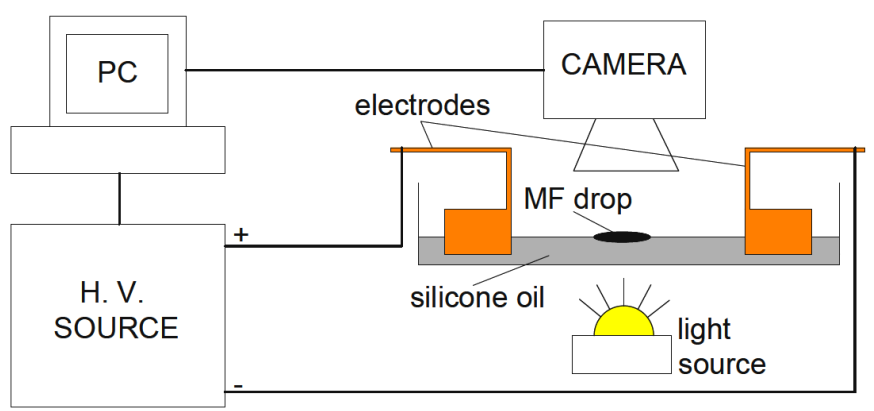

Fig. 1. Experimental set-up.

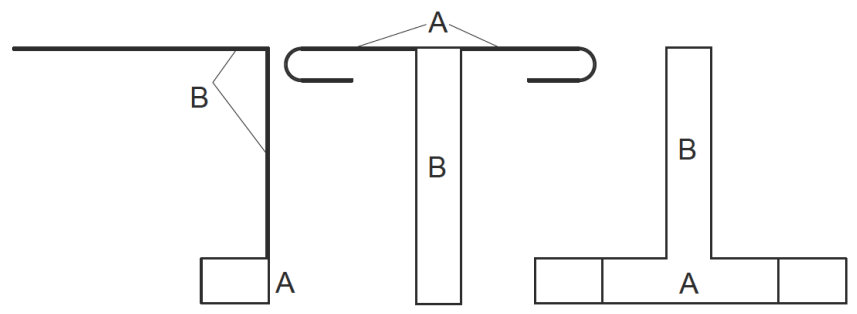

Fig. 2. Shape of copper electrode.

\section{Results and discussion}

The first experiment was to determine the dependence upon deformation parameter and time. The experiment was performed on MF with different concentration of nanoparticles and lasted $7 \mathrm{~s}$. Over a time greater than $7 \mathrm{~s}$ a drop breakup or a steady state occurred. The applied voltage was $1000 \mathrm{~V}$ and was constant at every time. The MF droplet deformation in time can be seen in Fig. 3. Droplets with different concentration deformed at all times until

the breakup occurred after $7 \mathrm{~s}$ but droplet with concentration $0.95 \%$ reached steady state at time $5 \mathrm{~s}$ as can be seen

in Fig. 4. This proves that MF droplet can stabilize where applied electric field does not cause further deformation. Since the $0.95 \%$ drop reached a steady state at a given electric field intensity $333 \mathrm{~V} / \mathrm{m}$, it implies that other concentrations would reach a steady state at a lower electric field intensity. Also from Fig. 4 it can be seen that at time $7 \mathrm{~s}$ deformation parameter decreases with increasing concentration.

\begin{tabular}{|c|c|c|c|c|}
\hline$\frac{\text { concentration }}{\text { time (s) }}$ & $0.95 \%$ & $0.65 \%$ & $0.35 \%$ & $0.15 \%$ \\
\hline 2 & 0 & 0 & $\bigcirc$ & 0 \\
\hline 3 & 0 & 0 & 0 & 0 \\
\hline 4 & 0 & 0 & 0 & 0 \\
\hline 5 & 0 & 0 & 0 & 0 \\
\hline 6 & 0 & 0 & 0 & $\diamond$ \\
\hline 7 & $\bigcirc_{2 \mathrm{~mm}}$ & $\bigcirc_{\frac{2 m m}{m}}$ & $\bigcirc_{2 \mathrm{~mm}}$ & 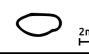 \\
\hline
\end{tabular}

Fig. 3. Deformation of MF droplet in time at constant applied electric field.

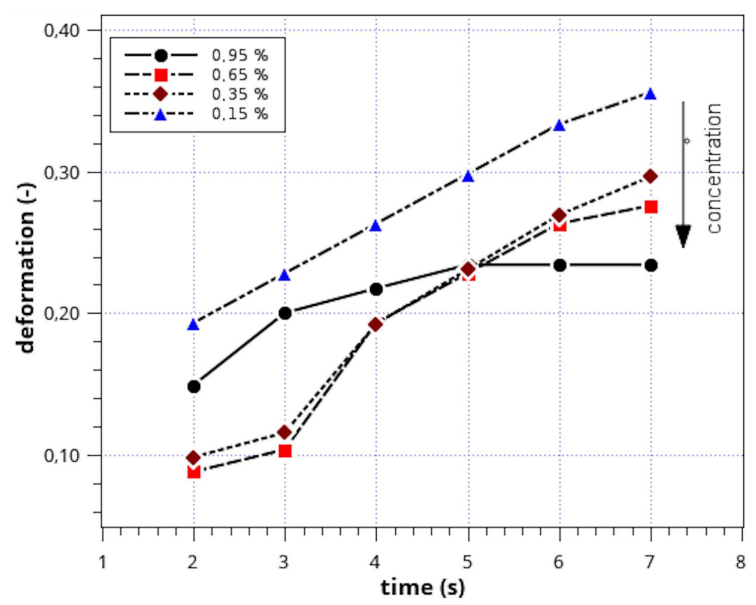

Fig. 4. Deformation parameter during time period.

Complete breakup of all droplets was by tip-streaming. According to Sherwood [16], a high probability of droplet deformation by tip-streaming can occur in liquid systems with a high relative permittivity, where the surface tension at the ends of the drop is weakened due to the in- 
fluence of the electric field. Changing the MF concentration can significantly affect the deformation process (time of deformation, shape of deformed drop, deformation parameter). In general, it is known that changes in the concentration also result in a change in the physical properties of the MF. When the concentration of MF is increasing so does the viscosity of MF. An increase in viscosity results in drown out shape of drop (Fig. 3).

The second experiment was to determine the dependence upon deformation parameter and change in electric field intensity. The voltage at generator was set in range from $600 \mathrm{~V}$ to $1200 \mathrm{~V}$ with step $200 \mathrm{~V}$ and distance between electrodes $3 \mathrm{~cm}$. The MF droplet deformation in dependence with applied electric field can be seen in Fig. 5. The deformation parameter was determined $5 \mathrm{~s}$ after electric field was applied. With increasing voltage the deformation parameter also increases (Fig. 6). It can be seen that rapid change in the deformation parameter of $0.15 \%$ and $0.35 \%$ droplets occurred at $800 \mathrm{~V}$. However, value of the deformation parameter of other droplets concentration changes linearly with increasing voltage.

\begin{tabular}{|c|c|c|c|c|}
\hline$\frac{\text { concentration }}{\text { test voltage }(\mathrm{V})}$ & $0.95 \%$ & $0.65 \%$ & $0.35 \%$ & $0.15 \%$ \\
\hline 600 & $\infty$ & 0 & 0 & 0 \\
\hline 800 & 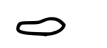 & 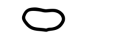 & 0 & 0 \\
\hline 1000 & $\hookrightarrow$ & 0 & 0 & 0 \\
\hline 1200 & $\bigotimes_{2 m m}$ & 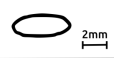 & 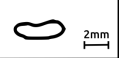 & $\bigcup_{2 \mathrm{imm}}$ \\
\hline
\end{tabular}

Fig. 5. Deformation of MF droplet at variable electric field.

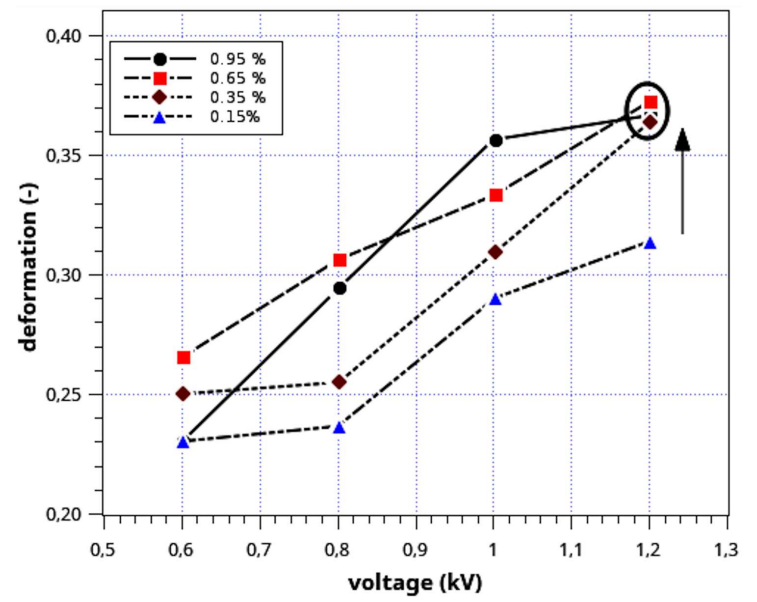

Fig. 6. Deformation parameter at variable electric field.

The drop breakup after $1200 \mathrm{~V}$ remained as same as from previous measurements. In Fig. 7 is pictured complete breakup of the droplet by tip-streaming at a voltage level of $1500 \mathrm{~V}$ and a concentration of $0.95 \%$. The deformation of magnetic fluid droplet in steady electric field is due to the polarisation of magnetic nanoparticles where the polarisation forces are actin on the droplet surface.

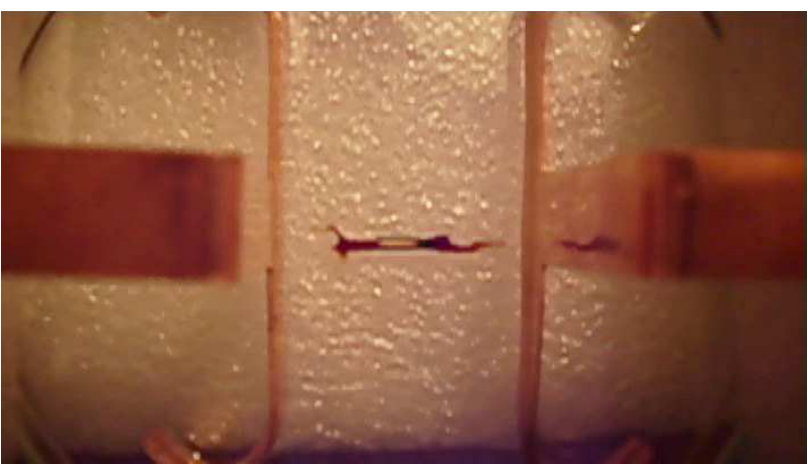

Fig. 7. $0.95 \%$ droplet breakup at $1500 \mathrm{~V}$.

\section{Conclusion}

The main achievement of this work was to provide an analysis of the deformation process of a MF drop suspended in a silicone oil when exposed to uniform electric field. We have compared the behaviour of four different MF under various conditions. From the results it can be seen that increasing electric field intensity and concentration of MF results in a change of the deformation process.

\section{Acknowledgement}

This work was supported by: Slovak Academy of Sciences and Ministry of Education in the framework of Projects VEGA No. 1/0132/15, 1/0311/15, and 2/0141/16; Ministry of Education Agency for structural funds of EU in frame of Projects No. 26220120003, 6220120046, 26220120055 and 313011D232. This work was supported by the Slovak Research and Development Agency under the contract No. APVV-15-0438.

\section{References}

[1] R.-Q. Lv, Y. Zhao, H. Li, H.-F. Hu, IEEE Trans. Magn. 51, 1 (2015).

[2] G. Thirupathi R. Singh, IEEE Trans. Magn. 51, 1 (2015).

[3] V. A. Primo, B. García, J. C. Burgos, in: Int. Conf. Dielectrics (ICD) Montpellier 2016, IEEE 2016, p. 76.

[4] A. Cavallini, F. Negri, in: Int. Conf. Dielectrics (ICD) Montpellier 2016, IEEE 2016, p. 88.

[5] L. Pislaru-Danescu, A.M. Morega, M. Morega, V. Stoica, O.M. Marinica, F. Nouras, N. Paduraru, I. Borbath, T. Borbath, IEEE Trans. Ind. Appl. 49, 1289 (2013).

[6] S. Chaudhari, S. Patil, R. Zambare, S. Chakraborty, in: 10th Int. Conf. Properties and Applications of Dielectric Materials, Bangalore 2012, IEEE 2012, p. 1. 
[7] J.G. Hwang, M. Zahn, F.M. O'Sullivan, L. A. Pettersson, O. Hjortstam, R. Liu, J. Appl. Phys 107, 14310 (2010).

[8] Ch.T. O'Konski, H.C. Thacher Jr., J. Phys. Chem. 57, 955 (1953).

[9] R.S. Allan, S.G. Mason, Proc. R. Soc. Lond. A 267, 45 (1962).

[10] G. Taylor, Proc. R. Soc. Lond. A 291, 159 (1966).

[11] J. Lyklema, Fundamentals of Interface and Colloid Science: Solid-Liquid Interfaces, Vol. 2, Academic Press, Cambridge 1995.

[12] R. Cimbala, J. Kurimský, M. Rajňák, K. Paulovičová, M. Timko, P. Kopčanský, M. Kolcun, M. Kosterec, S. Bucko, M. Kurimská, J. Elstat. 88, 55 (2017).
[13] M. Rajnak, J. Kurimsky, B. Dolnik, K. Marton, L. Tomco, A. Taculescu, L. Vekas, J. Kovac, I. Vavra, J. Tothova, P. Kopcansky, M. Timko, J. Appl. Phys 114, 034313 (2013).

[14] Jong-Wook Ha, Seung-Man Yang, J. Colloid Interface Sci. 206, 195 (1998).

[15] N.G. Trinh, IEEE Trans. Power App. Sys. 99, 1235 (1980).

[16] J.D. Sherwood, J. Phys. A: Math. Gen. 24, 4047 (1991). 